Volume 3, Issue 9, September-2016, pp. 471-475

ISSN (0): 2349-7084

International Journal of Computer Engineering In Research Trends

IJCERT

Available online at: www.ijcert.org

\title{
Investigate the effectt of approaching angle on cutting force during EN 8 steel turning
}

\author{
V. B. Magdum \\ Assistant Professor in Mechanical Engineering, \\ D.K.T.E. Society's Textle And Engineering Institute, Ichalkaranji, India \\ Email id: vbmagdum@rediffmail.com
}

\begin{abstract}
This paper deals ith the measurement of cutting force generated in turning for different cutting parameters and diferrent tools having various approaching angles while machining EN 8 steel. The approaching angles of the cutting tool were changed using selected parameters; and cutting force components were measured. The selected cutting variables and tools with diferrent approaching angles were tested practically under workshop conditions. During the experimentation, cutting speed and depth of cut were kept constant and each experiment was conducted with new sharp tools. Finally, the effects of cutting parameters and approaching angles on cutting force were analyzed. A cylindrical EN 8 workpiece was turned using carbide tools for three diferrent approaching angles $\left(60^{\circ}, 75^{\circ}\right.$ and $900^{\circ}$. A total 9 experiments were carried out with three feed rates $(0.065,0.13$ and $0.26 \mathrm{~mm} / \mathrm{rev})$ for each approaching angle, keeping the cutting speed (384 rpm) and depth of cut $(1 \mathrm{~mm})$ constant. During the experimentation forces were measured using dynamometer. The experimental result show that the thrust force were decreased by increasing approaching angles and feed force were increased by increasing approaching angles.
\end{abstract}

Keywords - Approaching angle, thrust force, feed force, dynamometer

\section{INTRODUCTION}

A manufacturing facility requires involvement of all production operations, technical possibility for full use or activation for an increase in productivity. Tool selection, combination of tool-workpiece, material and determination of cutting variables and tool geometry at optimum level must be considered for involvement of all the technological processes. The requirements for reliable technological information have increased due to more demanding manufacturing systems and this result in a reliable analysis in cutting in the cutting zone.

During cutting process, due to the relative motion between tool and workpiece the cutting tool penetrates into the workpiece and the cutting forces are measured on a measuring plane in the system. The cutting forces have been measured by the dynamometer. The cutting forces have been measured by the dynamometer. As the cutting force is very sensitive, even a smallest change in the cutting process is affected on cutting force. So, the selection of the conditions of the tests and experimental methodology is very important. The cutting parameters like depth of cut, tool mate- rial, cutting speed, feed rate, geometry and workpiece material type have significant effect on cutting force [1]-[5].

When the geometric variables like approaching angle changed using selected parameter range, the cutting force component variation generated.

\section{LITERATURE REVIEW}

An analysis in cutting in the cutting zone (cutter-workpiecechip system) is very critical. The mechanics of metal cutting in cutting zone are very complicated. It is not possible to make any precise statements about their mutual influences because various laws continuously interact ${ }^{[1]}$. The cutting forces have been measured by the dynamometers designed for different working principles as dial gauge indicator based, pneumatic based, strain gauge based [2, 3], load cell based ${ }^{[4]}$ and piezoelectric principle ${ }^{[5]}$. Zorev ${ }^{[6]}$ has stidied behavior of cutting force influenced by several variables in his study. Many cutting parameters such as cutting speed, 
feed rate, undeformed chip thickness, cutting tool material, tool geometry (approaching angle, rake angle, etc.), depth of cut and tool wear are influences on cutting force. A technique known as Mechanistic approach has been popular in predicting cutting forces, torque and power for a set of tool geometry and work material. Taylor ${ }^{[7]}$ determined the values of the cutting force components and Victor ${ }^{[8,9]}$ and specific cutting coefficient tables by using different rake angles, feed and speeds and offered applicable practical equations reported by Kienzle ${ }^{[10]}$ in their investigations,. Ernst and Merchant ${ }^{[11]}$ explained the chip formation process when analyzing the cutting process. They claimed that the chip was shaped in the sliding plane and was formed in the shear plane. The shear angle is depends on cleaving/wedge angle and friction and a characteristic variable. The influence of feed rate, cutting speed workpiece hardness, cutting edge geometry, and surface roughness on hardened AISI H13 steel bars with CBN tools are investigated by Fang and Jawahir [12].

The complimentary angle of side cutting edge angle is called the approach angle $(\varphi)$. By varying the approach angle, the thickness of the chip can be varied. For general turning of rigid work, the approach angle is maintained at $70^{\circ}$. When the geometric variables like approaching angle changed using selected parameter range, the cutting force component variation generated ${ }^{[13-14]}$.

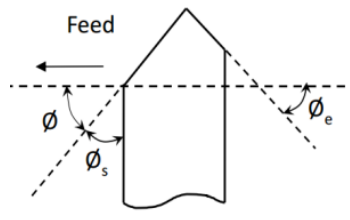

Fig. 1 Approach angle

The cutting forces direction and magnitude involved in machining processes help in design and selection of machine tools, cutting tools and accessories. The cutting force and its components generated on the tool point in the turning operation are shown in Fig. 2.

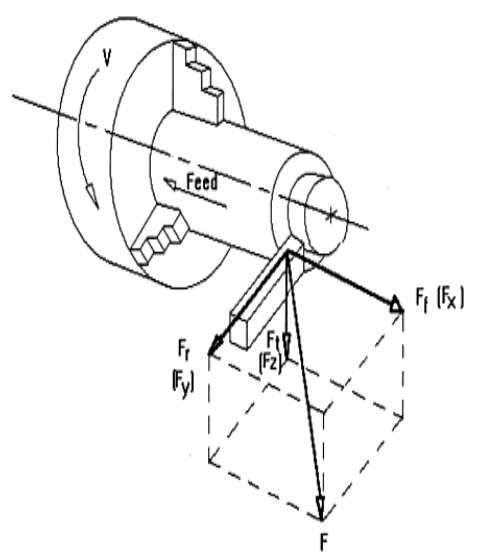

Fig. 2 Components of cutting forces
The resultant cutting force $\mathrm{F}$ as shown in Fig. 2 can be resolved along the three axes, viz. $\mathrm{X}, \mathrm{Y}$ and $\mathrm{Z}$ perpendicular whichare perpendicular toeach other. $F_{t}$ component acts in the direction of the cutting speed. $\mathrm{F}_{\mathrm{f}}$, the axial component, acts in the direction of the tool traverse and it is at right angles to $\mathrm{F}_{\mathrm{t} .} \mathrm{F}_{\mathrm{t}}$, the thrust or tangential component (shown vertically), determines the torque on the main drive mechanism, the deflection of the tool and the required power. It contributes very little to the power consumption. The radial component smaller in magnitude, $F_{r}$, acts along the tool shank and perpendicular to the other two components. It has no share in the power consumption ${ }^{[15]}$.

In this study, the effect of tool approaching angle on cutting force components was observed. A dynamometer was used for measuring thrust force $\left(\mathrm{F}_{t}\right)$ and feed force $\left(\mathrm{F}_{\mathrm{f}}\right)$ and the experiments were carried out on a turning machine.

\section{EXPERIMENTAL SETUP}

\section{Design of Experiment}

An experimental planning was made by using cutting parameters and test conditions that are considerd for toolworkpiece. In order to measure cutting forces such as, thrust force $\left(F_{t}\right)$ and feed force $\left(F_{f}\right)$ separately; a dynamometer was used. The dynamometer was equipped with strain gauge so that the thrust and feed component of cutting forces could be measured. The dynamometer consists of a sensing unit, tool holder and digital force indicator. Force signals coming from dynamometer were measured. EN 8 is most commonly used material in industry, hence selected to represent the major group of workpiece materials used in industry. Special parameter such as the chemical composition is shown in Table 1.

\begin{tabular}{|c|c|c|c|c|c|}
\hline $\mathrm{Fe}$ & $\mathrm{C}$ & $\mathrm{Mn}$ & $\mathrm{Si}$ & $\mathrm{P}$ & $\mathrm{S}$ \\
\hline 98.5 & 0.4 & 0.8 & 0.25 & 0.015 & 0.015 \\
\hline
\end{tabular}

Table 1 Chemical composition of EN8

For this study, EN8 steel bars were used. After the specimens were cut off in required length, cutting tests were performed on the specimen bars where the diameter was $\Phi 30$ $\mathrm{mm}$ and cutting length $100 \mathrm{~mm}$. The experimental set up is shown in Fig. 3. 
$90^{\circ}$ as shown in Fig. 4.

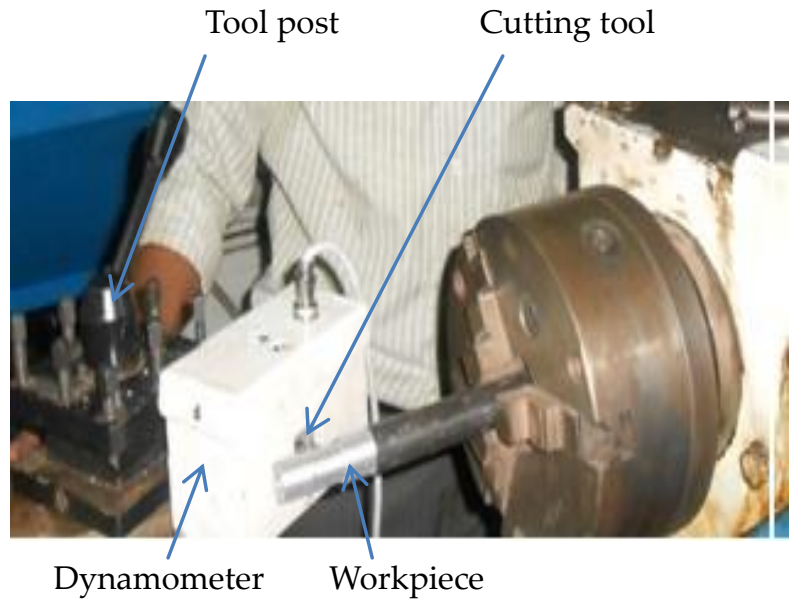

Fig.3 Experimental set-up

\section{Cutting tool and cutting parameter}

The cutting tests have been carried out on a lathe machine. By the different tool mountings designed for different approaching angle were used in single point turning operations on EN8 steel. Although the same tools were used in the tests, the approaching angles were changed as $60^{\circ}, 75^{\circ}$ and $90^{\circ}$ as shown in Fig. 4.

A carbide tool is used for machining is shown in Fig. 4. The hardness of the carbide is greater than the of most other tool materials at room temperature and it has the ability to retain its hardness at elevated temperatures to a greater degree, so that greater speeds can be adequately supported.

The cutting parameters feed rate ' $\mathrm{f}$ ' was assigned three different levels varying from $0.065,0.13$ and $0.26 \mathrm{~mm} / \mathrm{rev}$, cutting speed ' $v$ ' (384 rpm) and depth of cut 'd' $(1 \mathrm{~mm})$ were kept constant. In cutting conditions, small steps were used to increase the accuracy of the measured forces. Cutting parameters values are selected on the basis on the cutting tool manufacturer for general purpose and finish turning operations of EN8 steel. Each experiment was carried out with sharp tools in order to keep the cutting conditions unchanged. The experiments were conducted in dry conditions. As a result, totally 9 experiments were performed. The cutting parameters prepared for experimentation are given in Table 2.

\section{Cutting tool and cutting parameter}

The cutting tests have been carried out on a lathe machine. By the different tool mountings designed for different approaching angle were used in single point turning operations on EN8 steel. Although the same tools were used in the tests, the approaching angles were changed as $60^{\circ}, 75^{\circ}$ and

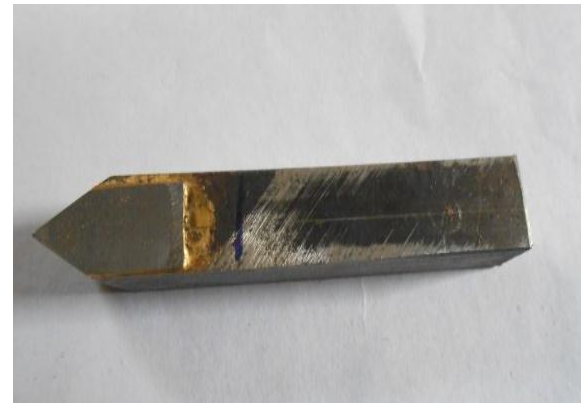

Fig. 4 Carbide cutting tool

The cutting parameters feed rate ' $f$ ' was assigned three different levels varying from $0.065,0.13$ and $0.26 \mathrm{~mm} / \mathrm{rev}$, cutting speed ' $\mathrm{v}$ ' and depth of cut ' $\mathrm{d}$ ' were kept constant as $384 \mathrm{rpm}$ and $1 \mathrm{~mm}$, respectively. Relaibility of measured forces is increased by taking small steps in cutting conditions. The cutting parameters were selected on the basis of tool manufacturer for general purpose and finish turning operations of EN8 steel. To keep the cutting conditions unchanged each experiment was carried out with sharp tools. Totally 9 experiments were performed in dry conditions. The cutting parameters prepared for all experiments are given in Table 2.

\begin{tabular}{|c|c|c|c|}
\hline $\begin{array}{c}\text { Cutting } \\
\text { speed } \\
\text { (rpm) }\end{array}$ & $\begin{array}{c}\text { Depth } \\
\text { of cut } \\
\text { (mm) }\end{array}$ & $\begin{array}{c}\text { Feed } \\
(\mathbf{m m} / \mathbf{r e v})\end{array}$ & $\begin{array}{c}\text { Approaching } \\
\text { angle }\end{array}$ \\
\hline 384 & 1.0 & 0.065 & $60^{\circ}$ \\
\hline 384 & 1.0 & 0.13 & $75^{\circ}$ \\
\hline 384 & 1.0 & 0.26 & $90^{\circ}$ \\
\hline
\end{tabular}

Table 2 Cutting parameter

In orthogonal cutting, the cutting is assumed as to be uniform along the cutting edge. Approaching angle which determines the tool and chip contact area plays a vital role in cutting force generation. There is generally an optimum value for approaching angle. Measured cutting forces for various cutting conditions as shown in Table 3.

Observation table

\begin{tabular}{|c|c|c|c|c|c|c|}
\hline $\begin{array}{c}\text { Sr. } \\
\text { No }\end{array}$ & $\begin{array}{c}\text { Cutting } \\
\text { speed } \\
\mathbf{( r p m )}\end{array}$ & $\begin{array}{c}\text { Feed } \\
\mathbf{( m m} / \\
\text { rev) }\end{array}$ & $\begin{array}{c}\text { Depth } \\
\text { of cut } \\
(\mathbf{m m})\end{array}$ & $\begin{array}{c}\text { Appro- } \\
\text { aching } \\
\text { angle } \\
\left.\mathbf{( \Phi}^{\circ}\right)\end{array}$ & $\begin{array}{c}\text { Thrust } \\
\text { force } \\
\mathbf{( N )}\end{array}$ & $\begin{array}{c}\text { Feed } \\
\text { force } \\
\mathbf{( N )}\end{array}$ \\
\hline 1 & 384 & 0.065 & 1 & 60 & 451 & 147 \\
\hline 4 & 384 & 0.065 & 1 & 75 & 432 & 167 \\
\hline
\end{tabular}


V. B. Magdum," Investigate the effectt of approaching angle on cutting force during EN 8 steel turning", International Journal of Computer Engineering In Research Trends, Volume 3, Issue 9, September-2016, pp. 471-475

\begin{tabular}{|l|l|l|l|l|l|l|}
7 & 384 & 0.065 & 1 & 90 & 373 & 206 \\
\hline 2 & 384 & 0.13 & 1 & 60 & 549 & 157 \\
\hline 5 & 384 & 0.13 & 1 & 75 & 500 & 186 \\
\hline 8 & 384 & 0.13 & 1 & 90 & 461 & 226 \\
\hline 3 & 384 & 0.26 & 1 & 60 & 608 & 167 \\
\hline 6 & 384 & 0.26 & 1 & 75 & 549 & 196 \\
\hline 9 & 384 & 0.26 & 1 & 90 & 481 & 245 \\
\hline
\end{tabular}

Table 3 Measured cutting forces for various cutting condtions

\section{Effect of Approaching ANGLe}

The side cutting edge approaches the workpiece with approaching angle. In large approaching angle, the cutting forces are distributed over a shorter section of the cutting edge. Since the side cutting edge at $90^{\circ}$ of approaching angle enters and leaves the cutting zone suddenly and it is subjected to maximum loading and unloading. With the same feed rate and depth of cut, At $60^{\circ}$, approaching angle the effective cutting edge length increased greatly comparing to the $90^{\circ}$. As a result, the chip thickness becomes smaller. The approaching angle affects the axial components of the cutting forces. A large feed force and also smaller thrust force produced by large approaching angle. The approaching angle also affects the direction of chip flow. As shown in Fig. 6 (a), at $0.065 \mathrm{~mm} / \mathrm{rev}$ feed rate; thrust force decreased by increased approaching angles and feed forces were increased. Fig. 6 (b), for the $0.13 \mathrm{~mm} / \mathrm{rev}$ feed rate, while feed force was increased, the thrust force was decreased. For the 0.26 $\mathrm{mm} / \mathrm{rev}$ feed rate, Fig. 6 (c), it was observed that the variation characteristic of cutting force was almost the same. As a result, for the changing of approaching angle in range of $60^{\circ}-75^{\circ}-90^{\circ}$, feed force component was increased, but thrust force was decreased.
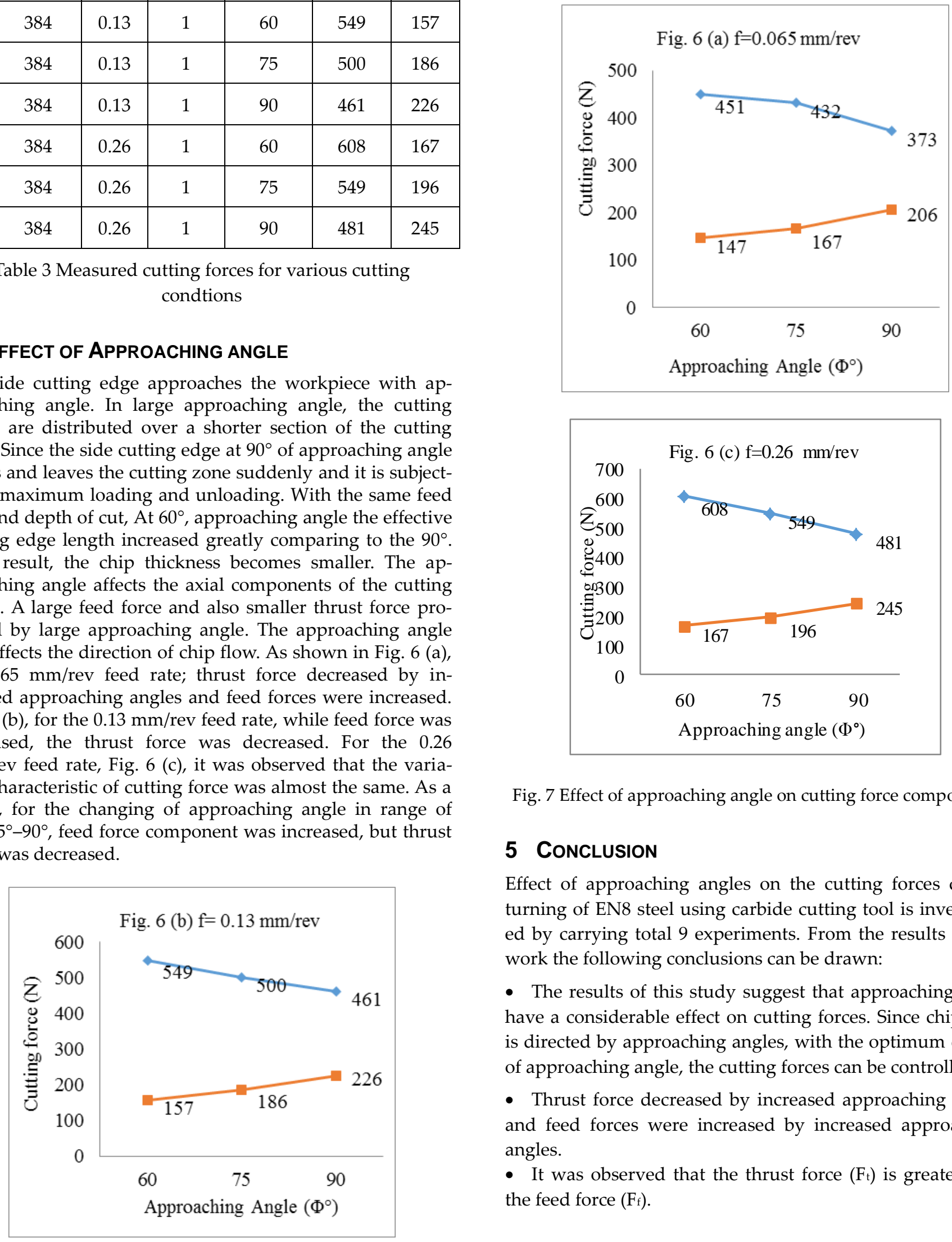

Fig. 7 Effect of approaching angle on cutting force components

\section{Conclusion}

Effect of approaching angles on the cutting forces during turning of EN8 steel using carbide cutting tool is investigated by carrying total 9 experiments. From the results of this work the following conclusions can be drawn:

- The results of this study suggest that approaching angle have a considerable effect on cutting forces. Since chip flow is directed by approaching angles, with the optimum design of approaching angle, the cutting forces can be controlled.

- Thrust force decreased by increased approaching angles and feed forces were increased by increased approaching angles.

- It was observed that the thrust force $\left(\mathrm{F}_{\mathrm{t}}\right)$ is greater than the feed force $\left(\mathrm{F}_{\mathrm{f}}\right)$. 
V. B. Magdum," Investigate the effectt of approaching angle on cutting force during EN 8 steel turning", International Journal of Computer Engineering In Research Trends, Volume 3, Issue 9, September-2016, pp. 471-475

It was observed that the thrust force $\left(\mathrm{F}_{\mathrm{t}}\right)$ and feed force $\left(\mathrm{F}_{\mathrm{f}}\right)$ increased with increase in feed rates.

\section{References}

[1] M.E. Merchant. Mechanics of the metal cutting process, ii. Plasticity conditions in orthogonal cutting. Journal of Applied Physics, vol. 16:318-324, 1945.

[2] M. Gunay, E. Aslan, I. Korkut, U. Seker, Investigation of the rake angle on main cutting force, Journal of Machine tools \& manufacture.2004, 44, 953-959.

[3] H. Saglam, F. Unsacar, S. Yaldiz, Investigation of the effect of rake angle and approaching angle on main cutting force and tool tip temperature, Journal of Machine tools \& manufacture.2006, 46,132-14. technology, new age international(P) limited, publications, Rajender sing 2006

[5] Tugrul O” zel ,Tsu-Kong Hsu, ErolZeren. Effects of cutting edge geometry, workpiece hardness, feed rate and cutting speed on surface roughness and forces in finish turning of hardened AISI H13 steel, International Journal of Advanced Manufacturing Technology. 2005, 25, 262-269.

[6] A.K. Baldoukas, F.A. Soukatzidis, G.A. Demosthenous, A.E. Lontos. Experimental investigation of the effect of cutting depth, tool rake angle and workpiece material type on the main cutting force during a turning process. Proceedings of the 3rd International Conference on Manufacturing Engineering (ICMEN), 1-3 October 2008

[7] Mustafa Gunay, Ihsan Korkut, Ersan Aslan, Ulvi Seker Experimental investigation of the effect of cutting tool rake angle on main cutting force, Journal of Materials Processing Technology. 2005,166, 44-49.

[8] Haci Saglam, Faruk Unsacar, Suleyman Yaldiz. Investigation of the effect of rake angle and approaching angle on main cutting force and tool tip temperature, International Journal of Machine Tools \& Manufacture.2006, 46, 132-141.

[9] D.I. Lalwani, N.K. Mehta, P.K. Jain.. Experimental investigations of cutting parameters influence on cutting forces and surface roughness in finish hard turning of MDN250 steel, journal of materials processing technology.2008, 206, 167-179.

[10] Tugrul O zel, Tsu-Kong Hsu, Erol Zeren. Effects of cutting edge geometry, workpiece hardness, feed rate and cutting speed on surface roughness and forces in finish turning of hardened AISI H13 steel, International Journal of Advanced Manufacturing Technology. 2005, 25, 262-269.

[11] H. Ernst, M.E. Merchant, Chip formation, friction and high quality machined surfaces, Transactions of the ASME 29 (1941) 299-328.

[12] N. Fang a, I.S. Jawahir. Analytical predictions and experimental validation of cutting force ratio, chip thickness, and chip back-flow angle in restricted contact machining using the universal slip-line model, International Journal of Machine Tools \& Manufacture.2002, 42, 681-694.

[13] HMT Banglore, "Production technology", Tata McGraw Hill Education Private Limited, ISBN: 978-0-07-096443-3, 32 ${ }^{\text {nd }}$ reprint 2011.

[14] P. C. Sharma, "A textbook of production engineering", S. Chand and Company limited, ISBN: 81-219-0421-8, 2005.

[15] G. R. Nagpal, "Machine tool engineering”, Khanna Publishers, ISBN:81-7409-046-0, 2003. 